\title{
Study on static and creep properties of CFRP using rubber modified matrix
}

\author{
K. Takemura ${ }^{1} \&$ Y. Yasuda ${ }^{2}$ \\ ${ }^{I}$ Department of Mechanical Engineering, Kanagawa University, Japan \\ ${ }^{2}$ Graduate Student of Kanagawa University, Japan
}

\begin{abstract}
In this study, the static and creep properties of Carbon Fiber Reinforced Plastics (CFRP) are examined. Plain woven carbon fabric is used as reinforcement. As the matrix, epoxy resin is modified by using cross-linked rubber particles. Four weight contents $(0 \%, 5 \%, 10 \%$, and $15 \%)$ of rubber modification are used. Three point bending loading is applied to the specimen. Static and creep tests are conducted. The results can be summarized as follows.

For epoxy resin bulk and CFRP specimens, the strength and maximum strain decrease by rubber modification at static bending test, but the reduction rates of the strength and maximum strain for CFRP are smaller than those of resin bulk specimens. For example, when the weight content of rubber particles for epoxy resin is $5 \%$, the strength reduces to about $50 \%$ and the maximum strain reduces to about $60 \%$ in the resin bulk specimen, but the strength and maximum strain reduce to about $35 \%$ and $25 \%$ respectively in CFRP. For the creep test, the creep strain rate in the secondary state is improved for CFRP with rubber modification. When the weight content of rubber particles is big, the improvement of the creep strain rate in the secondary state is great. For example, for CFRP whose weight content of rubber particles is $15 \%$, the creep strain rate decreases by $25 \%$. When an environmental temperature is beyond 120 degrees centigrade, the creep strain rate at the secondary state increases rapidly for unmodified CFRP, but the creep strain rate for modified CFRP is not so increased. So, an effect of rubber modification is great in the high temperature environment. In the case when the environmental temperature is 190 degrees centigrade, a 5\% modification is most effective. Consequently, the rubber modification method for CFRP is effective for creep strain in an elevated temperature environment.
\end{abstract}

Keywords: CFRP, epoxy, rubber modification, creep, bending loading. 


\section{Introduction}

CFRP has high specific strength and modulus compared to conventional metal materials. So, CFRP is widely used in automobile and airplane parts. When CFRP is used as the structural materials of airplane wings, constant load is supplied for several hours. So, the creep property for CFRP is important. Static and creep properties are dependent on environmental temperature because the polymer matrix is used. Therefore, the mechanical properties at elevated temperature are important too. In the case that epoxy matrix of CFRP is modified with cross-linked rubber particles, the static tensile strength and fatigue lives of CFRP have increased $[1,2]$. But, as far as the authors know, few papers have been published about the effect of rubber particle to creep properties for CFRP.

The objective of this present work is to demonstrate the static and creep properties for CFRP with a rubber modified matrix. The effect of environmental temperature on the properties is also examined.

\section{Specimens}

Plain woven carbon fabric (Toray Co.) is used as reinforcement. The number of laminates is eight. Epoxy resin is used as the matrix. The matrix is modified by using cross-linked rubber particles. Four weight contents $(0 \%, 5 \%, 10 \%$, and $15 \%$ ) of rubber particle are used. Specimens are laminated by the hand lay up method, and they are cured by a hot press facility. The pressure at moulding is about $10 \mathrm{MPa}$. The length, breadth and thickness of the specimens are $100 \mathrm{~mm}$, $15 \mathrm{~mm}$ and $2 \mathrm{~mm}$ respectively.

\section{Experiment}

\subsection{Static bending test}

Three point bending tests are conducted with Shimadzu universal testing instruments (AG-IS). Crosshead speeds are $2.0 \mathrm{~mm} / \mathrm{min}$ for resin bulk and 5.0 $\mathrm{mm} / \mathrm{min}$ for CFRP specimens. An extensometer (MTS Co.) is used to measure a strain. The number of specimens is five at one test condition based on JIS (Japanese Industrial Standard) 7171 and 7074.

\subsection{Creep test}

Constant temperature oven facility (Advantec Co.) is used for the creep test. Three point bending loading $(20 \mathrm{~N})$ is applied. The deflection is measured and recorded with a remote scanner (NEC Co.). The creep test continues until failure or near 150 hours. Environmental temperatures are 110, 120, 130 and 190 degrees centigrade. 


\subsection{Observation of flat wise surface}

In the case of creep test, flat wise surfaces are observed with a scanning electron microscope (SEM-EDX: Hitachi Co.)

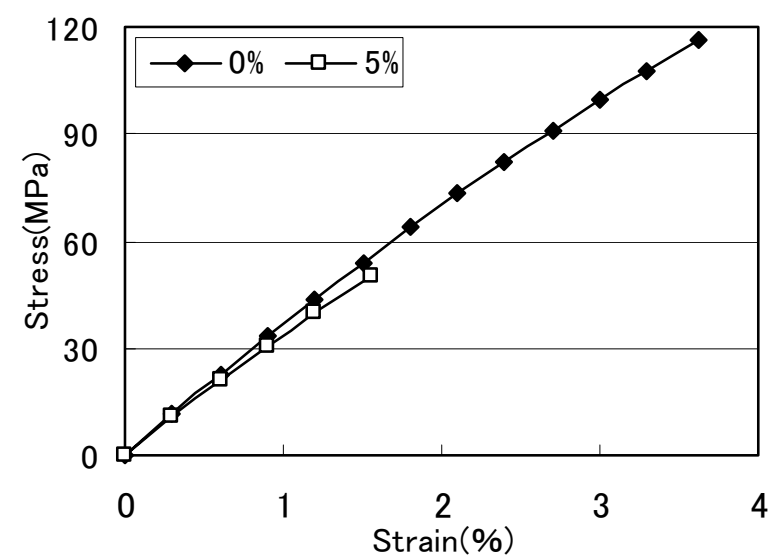

Figure 1: Stress-strain curves for epoxy resin bulk.

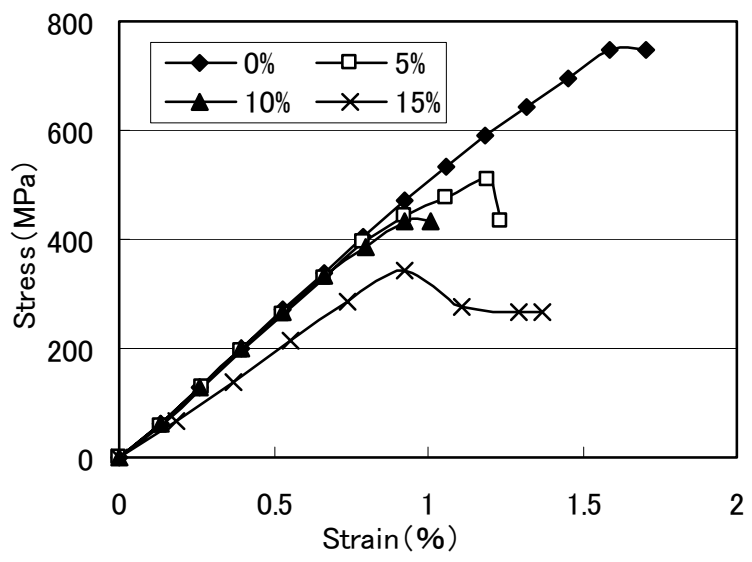

Figure 2: $\quad$ Stress-strain curves for CFRP.

\section{Results and discussion}

\subsection{Static bending test}

Figure 1 shows stress-strain curves for a resin bulk specimen which has no reinforcement. Figure 2 shows stress-strain curves for CFRP. Table 1 and table 2 show the mechanical properties for resin bulk and CFRP respectively. From these results, it is understood that the strength (maximum stress) and maximum strain decrease by rubber modification for resin bulk and CFRP. It is because of 
Young's modulus that the decrease is due to the rubber modification to the matrix. The reduction rates for CFRP are smaller than that of resin bulk specimen. When the weight content of rubber particles for the epoxy resin bulk is $5 \%$, the strength reduces by about $50 \%$ and the maximum strain reduces by about $60 \%$. But the strength reduces by about $35 \%$ and the maximum strain reduces by about $25 \%$ for CFRP. So, the reduction of mechanical properties for CFRP is smaller than that of resin bulk.

Table 1: $\quad$ Mechanical property for epoxy resin bulk at static bending test.

\begin{tabular}{|c|c|c|c|}
\hline & $\begin{array}{c}\text { Maximum } \\
\text { stress } \\
(\mathrm{MPa})\end{array}$ & $\begin{array}{c}\text { Maximum } \\
\text { Strain } \\
(\%)\end{array}$ & $\begin{array}{c}\text { Young's } \\
\text { modulus } \\
(\mathrm{GPa})\end{array}$ \\
\hline $0 \%$ & 116 & 3.62 & 3.8 \\
\hline $5 \%$ & 50 & 1.55 & 3.5 \\
\hline
\end{tabular}

Table 2: $\quad$ Mechanical property for CFRP at static bending test.

\begin{tabular}{|c|c|c|c|}
\hline & $\begin{array}{c}\text { Maximum } \\
\text { stress } \\
(\mathrm{MPa})\end{array}$ & $\begin{array}{c}\text { Maximum } \\
\text { Strain } \\
(\%)\end{array}$ & $\begin{array}{c}\text { Young' s } \\
\text { modulus } \\
(\mathrm{GPa})\end{array}$ \\
\hline $0 \%$ & 778.4 & 1.68 & 47.0 \\
\hline $5 \%$ & 514.9 & 1.21 & 46.6 \\
\hline $10 \%$ & 440.6 & 0.96 & 47.0 \\
\hline $15 \%$ & 349.2 & 1.00 & 34.3 \\
\hline
\end{tabular}

\subsection{Creep test}

Figures 2-5 show the relationships between creep strain and time in 110, 120, 130 and 190 degrees centigrade respectively. Creep curve can be divided into three stages. The first stage is the transient creep region which includes the elastic strain region. The second one is constant creep region which is called secondary creep, and the last one is the tertiary creep region. So, creep strain $\varepsilon$ at first and second stages can be written as follows.

$$
\begin{gathered}
\varepsilon=\varepsilon_{0}+\beta t^{n}+k t \\
\varepsilon_{0}: \text { elasticity strain } \quad t \text { : time } \\
\beta t^{n}: \text { strain of transient creep region } \\
k t: \text { strain of secondary creep region }
\end{gathered}
$$


Figure 7 shows coefficients $k$ of creep curves at each temperature environment. The coefficient $k$ decreases as the rubber contents increase. From fig.3 and 7, when the temperature is 110 degrees centigrade, the strain of the secondary creep region is small. From the viewpoint of static property, Young's modulus decreases with the increase of rubber content. Therefore, it is thought that the creep strain at 110 degree centigrade is dependent on the static property especially Young's modulus.

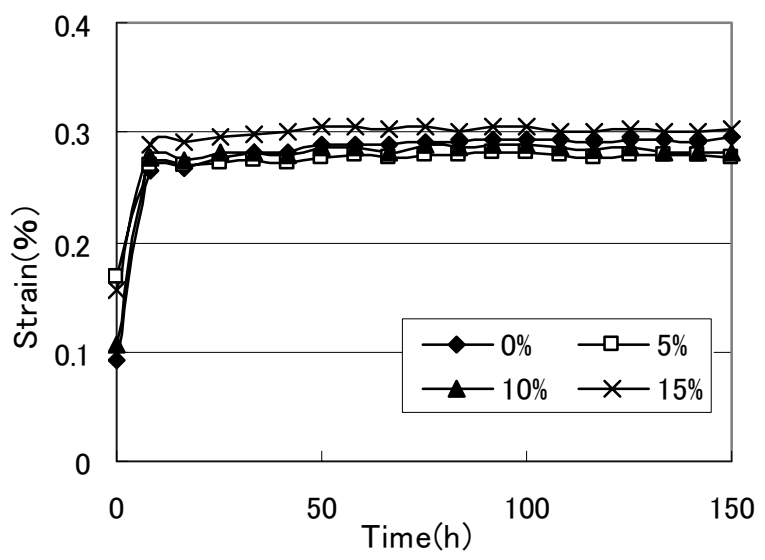

Figure 3: $\quad$ Relationship between strain and time $\left(110^{\circ} \mathrm{C}\right)$.

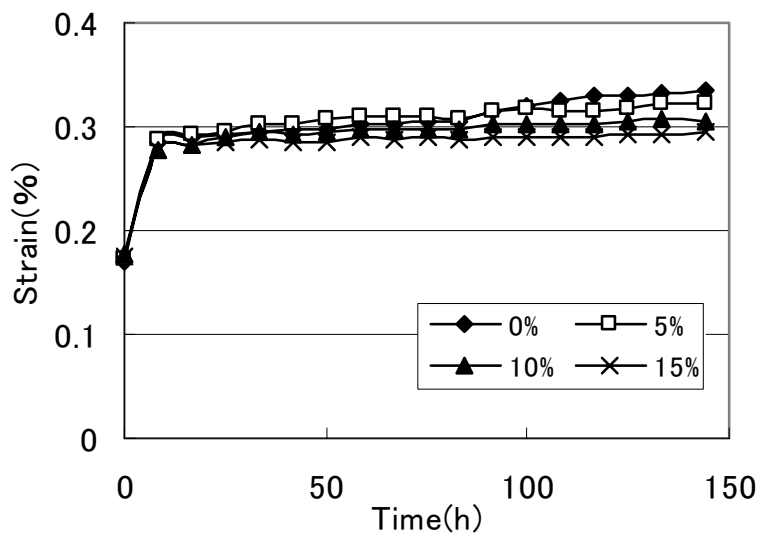

Figure 4: $\quad$ Relationship between strain and time $\left(120^{\circ} \mathrm{C}\right)$.

In the case that the environment temperature is beyond 120 degrees centigrade, secondary creep strain rate becomes big which are seen in figs 4 and 5. From Fig.7, the effect of rubber modification to the creep strain is great in the 
high temperature environment. Epoxy resin has glassy property under some temperature which is thought 125 degrees centigrade [3]. But, this temperature is affected by a quantity and a kind of hardening agent. Therefore, it is thought that the temperature decrease to 115 degrees centigrade. In addition, it is known that the creep property is improved by crumb rubber modified to bitumen. Therefore, it is thought that the creep property of CFRP is improved with rubber modification.

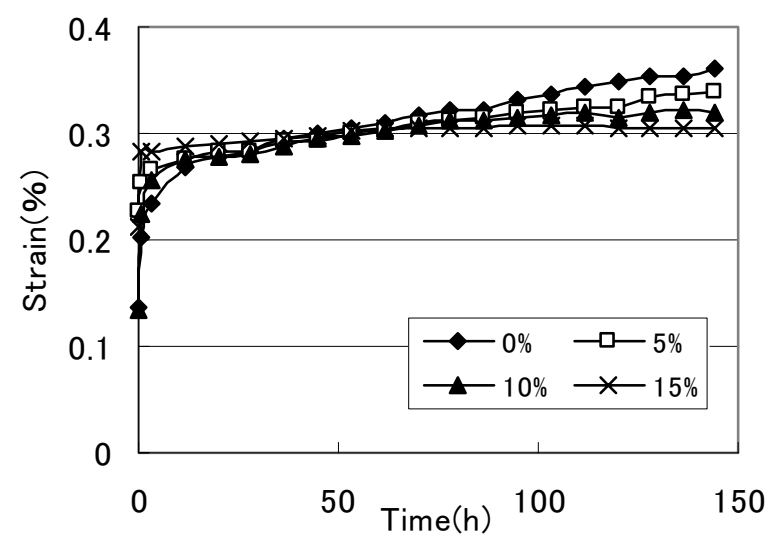

Figure 5: $\quad$ Relationship between strain and time $\left(130^{\circ} \mathrm{C}\right)$.

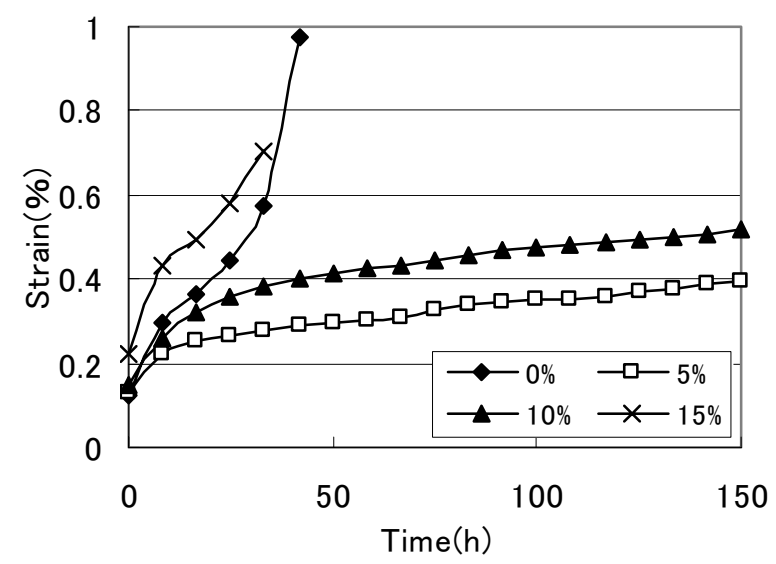

Figure 6: $\quad$ Relationship between strain and time $\left(190^{\circ} \mathrm{C}\right)$.

In the case that the environmental temperature is 190 degrees centigrade (Fig.6), unmodified and 15\% modified specimen fails rapidly. But, 5\% and 10\% modified specimens do not fail until 150 hours. So, excess modification is not effective for an extreme high temperature environment. 


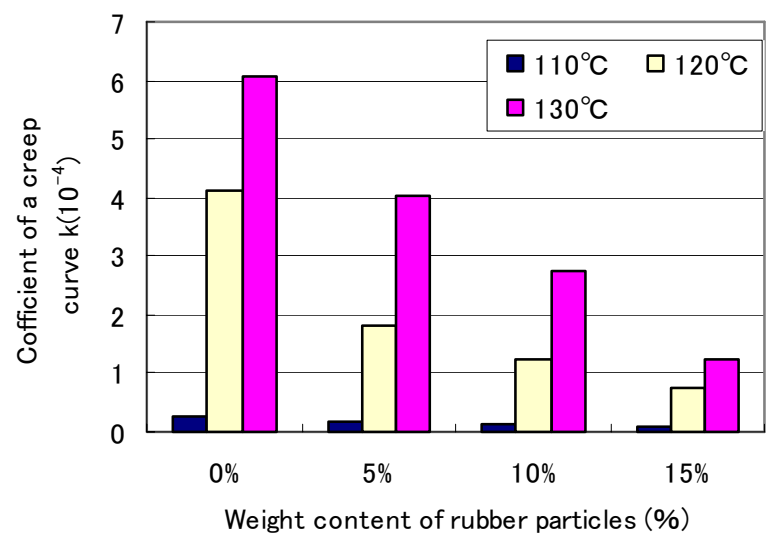

Figure 7: Coefficient of creep curve $k$.

After the creep test, flat wise surfaces of CFRP are observed with SEM. Figure 8 shows SEM micrograph. The images can be compared with that at 25 degrees centigrade. In the case of 110 degrees centigrade, it looks like the same as that of 25 degrees centigrade. In the case of 120 degrees centigrade, fibers can be seen on the surface. In the case of 190 degrees centigrade, fibers can be seen on the surface clearly. In addition, the weight of specimen in 190 degrees centigrade decreases 1.3 percent. Therefore, it is thought that epoxy resin is removed from the surface when the environmental temperature is 190 degrees centigrade.

In the case that the temperature is above 120 degrees centigrade, it is thought the resin may be removed. So, the secondary creep strain rate of CFRP increases rapidly over 120 degrees centigrade.

\section{Conclusions}

The effect of rubber modification to static and creep properties for CFRP is examined. In the result, following conclusions are obtained.

For static test, the mechanical properties decrease due to rubber modification. The reduction rate of CFRP is smaller than that of resin bulk.

For creep test at elevated temperature, in the case that the weight content of rubber particles is big, there is an improvement of creep strain rate in the secondary state. Therefore, the rubber modification method has an effect to creep strain rate in secondary region. When the environmental temperature is above 120 degrees centigrade, epoxy resin is removed due to the heat. Therefore, this phenomena affects the acceleration of creep strain rate. 
10 Computational Methods and Experiments in Materials Characterisation III

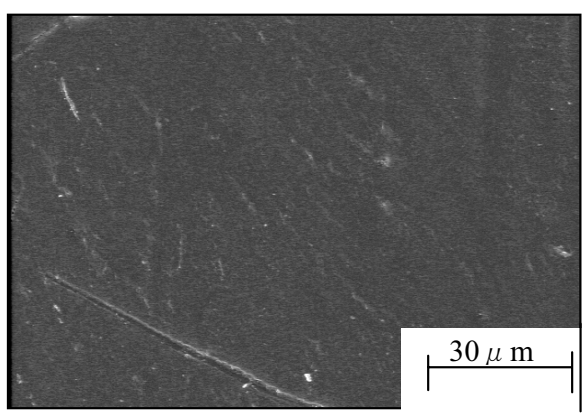

(a)

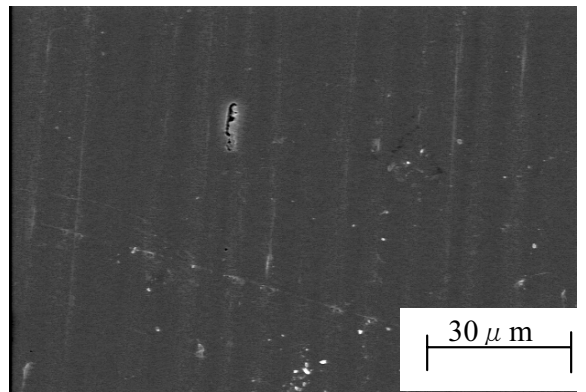

(b)

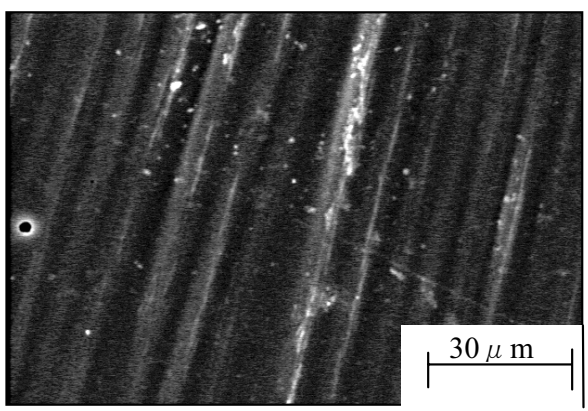

(c)

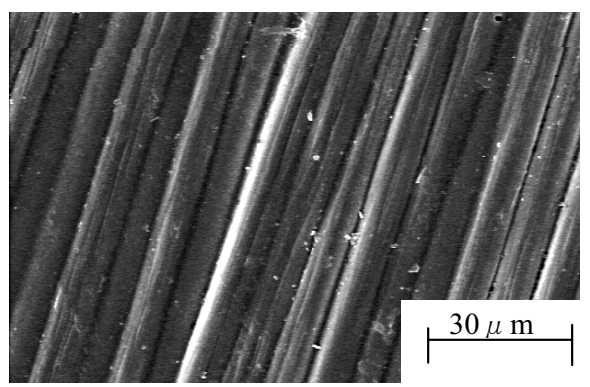

(d)

Figure 8: $\quad$ (a) $25^{\circ} \mathrm{C}$, (b) $110^{\circ} \mathrm{C}$, (c) $120^{\circ} \mathrm{C}$, (d) $190^{\circ} \mathrm{C}$ SEM image of CFRP. 


\section{References}

[1] K. Takemura and T. Fujii, Improvement in Static, Impact and Fatigue Properties of CFRP due to CNBR Modification of Epoxy Matrix, JSME International Journal Series A, Vol.43, No.2, pp.186-195, 2000.

[2] M. Higashino, K. Takemura and T. Fujii, Strength and damage accumulation of carbon fabric composites with a cross-linked NBR modified epoxy under static and cyclic loadings, Composite Structures, Vol.32, No.1-4, pp.357-366, 1995

[3] Engineering Materials Handbook, Vol.1 Compoiste, ASM International, pp.66-77, 1987.

[4] Sharma, V., Goyal, S., Comparative study of performance of natural fibres crumb rubber modified stone matrix asphalt mixtures. Canadian Journal of Civil Engineering, 33(4), pp134-139, 2006. 